\title{
Ciencia, científicos y guerra en el siglo xx: algunas cuestiones ético-morales
}

\author{
JOSE MANUEL SANCHEZ RON \\ Universidad Autónoma de Madrid
}

En este artículo se estudian diferentes cuestiones relativas a la dimensión éticomoral de la ciencia, utilizando para ello aportaciones realizadas por científicos a las dos guerras mundiales de nuestro si-

glo. Entre tales cuestiones se encuentran la relevancia de la teoría de la guerra justa, la actitud trascendentalista de los científicos y sus consecuencias político-morales, y la disuasión nuclear.

Si hay un siglo que ofrezca materiales de base para estudiar -desde el punto de vista de la historia, la filosofía o la economía- las relaciones entre ciencia y guerra, ese es el siglo Xx. Están, por supuesto, las dos guerras mundiales, pero no sólo ellas, sino también toda una pléyade de conflictos que, aunque no tuvieron extensión idéntica, ofrecen asimismo numerosos ejemplos de la utilización de la ciencia y la tecnologia fuertemente dependiente del conocimiento científico en los conflictos bélicos. Además, la dimensión "militarista" de la ciencia no se agota con su aplicación a las guerras "reales», plasmadas en batallas, muertes o estrategias, sino que también hay que tomar en cuenta la participación de la ciencia y de los científicos en las Fuerzas Armadas en tiempos de paz. Como proveedores, por ejemplo, de nuevas armas. Por último, tenemos ese nuevo instrumento, hecho posible por la ciencia, que es la disuasión nuclear, con el que la violencia bélica se convierte en potencialmente permanente.

\section{La teoria de la guerra justa y la Primera Guerra Mundial}

Entre las distinciones que han surgido de los análisis éticos de la guerra,' se encuentra la concepción realista, según la cual la guerra está justificada cuando sirve al interés nacional, e injustificada cuando va en contra de él, siendo considerados los intereses de los demás Estados o naciones relativamente irrelevantes. Las evidentes y numerosas objeciones que se pueden oponer a semejante planteamiento hacen que durante nuestro siglo pocas veces dirigentes políticos o ciudadanos individuales hayan intentado defender sus iniciativas bélicas en base a este tipo de concepción. Pocas veces, pero no nunca. Las intervenciones militares de la Alemania hitleriana se 
cuentan entre las más primitivas, aquellas en las que menos se cuidó el aspecto argumental, y en este sentido las más cercanas a la concepción realista, de la historia de la guerra de los últimos siglos en los países más desarrollados.

Una concepción ética diferente de la guerra, a medio camino entre el pacifismo y el realismo, es la conocida como "teoría de la guerra justa». Según esta idea, igual que la violencia política nacional puede ser legítima siempre que pretenda servir fines justos y bien especificados y que esté regida y limitada por normas, también puede ser legítimo el uso de la violencia por el Estado contra las amenazas exteriores siempre que los fines sean justos y los medios sujetos a las limitaciones adecuadas.

La teoría de la guerra justa, según la cual se desarrollan la mayoría de los tratamientos actuales de la ética de la guerra, tiene dos componentes: una teoría de los fines y una teoría de los medios. La primera de éstas, conocida como la teoría del ius ad bellum (derecho a la guerra), define las condiciones en las que es permisible recurrir a la guerra, siendo su elemento o exigencia principal el que ésta debe librarse por una causa justa. La segunda teoría, la del ius in bello (derecho en la guerra), establece los límites de la conducta permisible en la guerra.

La teoría del ius in bello consta, según Jeff McMahan, de tres requisitos: 1) el de la fuerza mínima (la cantidad de violencia utilizada en cualquier ocasión no debe exceder la necesaria para alcanzar el fin propuesto); 2) el de proporcionalidad (las malas consecuencias esperadas de un acto de guerra no deben superar, o ser mayores que sus esperadas consecuencias buenas); y 3) el de la discriminación (sólo debe aplicarse la fuerza contra las personas que constituyen legítimos objetivos de ataque).

Es bien sabido que todos estos límites, tanto en lo que se refiere al ius ad bellum como al ius in bello, chocan con graves dificultades a la hora de enfrentarse con la realidad. La historia de la ciencia muestra este hecho con bastante claridad. En el caso, por ejemplo, de la Primera Guerra Mundial.

Aunque pueda parecer una trivialidad, conviene recordar que los científicos no son inmunes a los ambientes en los que se mueven. Max Born, uno de los creadores de la mecánica cuántica (entre sus aportaciones se encuentra la interpretación probabilista de la función de ondas) y un «nacionalista" germano bastante moderado, constituye un buen ejemplo en este sentido. Pues bien, en sus memorias Born escribía:2

En 1914 tuvo lugar un estallido patríotico de entusiasmo en todos los países. En Gotinga lo tuvimos en todo su apogeo: banderas, desfiles y canciones. Las tropas desfilaban por las calles entre las gentes que les lanzaban flores. Banderas por todas partes, en las calles y en los trenes que llevaban a los soldados al frente [...] El delirio patrítico se vio acompañado de rumores incontrolados y de una caza de espías: se decía que los pozos estaban envenenados, los caballos del regimiento 
paralizados, puentes dinamitados. Todos los extranjeros fueron puestos bajo custodia [...] Los periódicos estaban repletos de artículos patrióticos. Yo odiaba la guerra, pero no podía escapar a la influencia de la propaganda. Creía, como todos los demás, que Alemania habia sido atacada, que estaba luchando por una causa noble y que su existencia estaba en juego [...]

No puedo negar que durante aquel tiempo me sentí muy en contra de los ingleses, de los franceses y sobre todo de los rusos. Todos los dias nos contaban las abominables atrocidades de los cosacos de la Prusia del Este. La idea de estas "hordas asiáticas" destruyendo los agradables y ordenados pueblos alemanes torturaba a las mujeres y niños y a mi me enfurecía.

En esta atmósfera de excitación, el 4 de octubre de 1914, movidos en parte por las negativas repercusiones que había tenido en el mundo la invasión de Bélgica, 93 intelectuales alemanes daban a conocer lo que denominaron "Aufruf an die Kulturwelt» (Llamamiento al mundo civilizado). ${ }^{3}$ Entre esos intelectuales figuraban 15 «científicos de la naturaleza»: Adolf von Baeyer (catedrático de química, Munich), Karl Engler (química, Karlsruhe), Emil Fischer (química, Berlín), Wilhelm Förster (astronomía, Berlín), Fritz Haber (química, Berlín), Ernst Haeckel (zoología, Jena), Gustav Hellmann (meteorología, Berlín), Felix Klein (matemáticas, Gotinga), Philipp Lenard (física, Heidelberg), Walter Nernst (físico-química, Berlín), Wilhelm Ostwald (química, Leipzig), Max Planck (física, Berlín), Wilhelm Röntgen (física, Munich), Wilhelm Wien (física, Würzburg) y Richard Willstätter (química, Berlín). Los restantes firmantes se repartían de la siguiente manera: 17 artistas, 12 teólogos (entre los que figuraba el célebre Adolf von Harnack, director general de la Biblioteca de Berlín, encargado también de dirigir la política cultural de Prusia en estrecha colaboración con el responsable de los asuntos universitarios del ministerio prusiano de Cultura, Theodor Althoff), 9 poetas, 7 historiadores, 7 juristas, 7 médicos (incluyendo al conocido Paul Ehrlich, premio Nobel de Medicina y Fisiología en 1908 y catedrático de bacteriología en la Universidad de Berlín), 5 escritores de temas artísticos, 4 filósofos, 4 filólogos, 3 músicos, 2 politólogos y el director del Deutschen Theaters de Berlín.

Mucho más que cualquier otro hecho, este documento enturbiaría durante años las relaciones entre los científicos de la Entente y los Aliados. Pero lo que me interesa en la presente ocasión es resaltar la escasa ecuanimidad, la despreocupación por ponerse en la situación del "otro", por intentar comprender sus argumentos, que mostraron estos intelectuales. En primer lugar, se consideraban depositarios de «la Verdad»:

Nosotros, representantes de la ciencia y el arte alemanes, delante de todo el mundo, contra las mentiras y calumnias detrás de las que nuestros enemigos pretenden ocultar la causa pura de Alemania, en la difícil lucha que se le ha impuesto [...] proclamamos la verdad. 
Para aquellos 93 intelectuales, la élite de la ciencia y el pensamiento alemán, no era verdad «que Alemania haya sido la causante de la guerra. $\mathrm{Ni}$ el pueblo, ni el Gobiemo, ni el Emperador la han querido. Se ha hecho todo lo posible por evitarla desde la parte alemana. El mundo posee sobre esta cuestión documentos irrefutables. A lo largo de los veintiséis años de su reinado, Guillermo II ha demostrado muchas veces que es el protector de la paz mundial; muchas veces sus adversarios lo han reconocido. $Y$ durante años se han burlado de este mismo Emperador, que ahora osan llamar un Atila, a causa de su amor a la paz. Solo ha sido cuando fuerzas preponderantes, que desde hace mucho tiempo se encontraban al acecho en nuestras fronteras, se han lanzado sobre nuestro pueblo desde tres lados, que éste se ha levantado como un solo hombre».

La teoría de la guerra justa -en concreto, la teoría del ius ad bellum-, alloraba a continuación, cuando declaraban:

No es verdad que hayamos violado de una manera criminal la neutralidad de Bélgica. Nos habríamos destruido a nosotros mismos si hubiésemos tomado la delantera.

Inmediatamente, se embarcaban en argumentos típicos de la teoría del ius in bello, con sus requisitos de la fuerza mínima, proporcionalidad y discriminación; es decir, los límites del comportamiento permisible en la guerra (otra cosa es que las justificaciones que se empleaban fuesen correctas; en general no lo eran):

No es cierto que nuestros soldados hayan tocado la vida y la propiedad de un solo ciudadano belga sin haber sido empujados a ello por sus defensores. Porque, todavia y siempre, a pesar de todas las advertencias, la población les ha preparado emboscadas para disparar sobre ellos, mutilando heridos, asesinando médicos mientras desempeñaban su obra de samaritanos.

No es verdad que nuestras tropas hayan saqueado brutalmente Lovaina. Ellas se han visto obligadas a tomar represalias contra los habitantes furiosos que les han asesinado traidoramente, y con un corazón cariacontecido han bombardeado la ciudad. La mayor parte de Lovaina ha sido conservada. El célebre Ayuntamiento permanece brillantemente intacto. Con peligro de sus vidas, nuestros soldados lo han protegido de las llamas. Si se han destruido obras de arte durante esta guerra terrible, si otras seguirán el mismo camino, todo alemán lo lamentará. Pero mientras que no nos dejaremos sobrepasar por nadie en lo que al amor al arte se refiere, rechazamos exponernos a una derrota por la conservación de un monumento artístico.

No es verdad que nuestra forma de hacer la guerra ignore el derecho de gentes. Tal forma no conoce crueldades indisciplinadas.

Pero en el "Manifiesto de los 93» también se encuentran otros argumentos más difíciles de encajar dentro de una cobertura teórica ética: 
No es verdad que la lucha contra lo que se ha llamado nuestro militarismo no sea una lucha contra nuestra cultura, como pretenden hipocritamente nuestros enemigos. Sin el militarismo alemán, la cultura alemana habría desaparecido de la faz de la tierra hace mucho tiempo. Es para proteger esa cultura, que un país que durante siglos ha sufrido más invasiones que ningún otro, ha salido de sus fronteras. El ejécrito y el pueblo alemanes forman una unidad. Semejante convicción une hoy día a 70 millones de alemanes, sin distinción de educación, condición social y partido.

No podemos arrancar a nuestros enemigos el arma cnvencnada de la mentira. Lo único que podemos hacer es proclamar en el mundo entero que han presentado un falso testimonio; $y$ es a vosotros, que nos conocéis, que hasta ahora habéis vigilado con nosotros los bienes supremos de la humanidad, a quien apelamos.

¡Crecdnos! Creed que llevaremos el combate hasta el final, como un pueblo cultivado al que la herencia de Goethe, de Beethoven y de Kant es tan sagrada como su hogar y su tierra. Nos hacemos garantes de ello con nuestro nombre y nuestro honor.

En la atmósfera que reinaba entonces en Alemania era difícil -y arriesgado- oponerse públicamente a semejante declaración. Sin embargo, pocos días después de su publicación un destacado pacifista alemán, Georg Friedrich Nicolai, catedrático de fisiología en la Universidad de Berlín, preparó una réplica que hizo circular entre sus colegas universitarios. Sólo tres personas se adhirieron a ella: uno de ellos era Albert Einstein, que en la primavera de 1914 había abandonado Zurich instalándose en un atractivo puesto sin obligaciones docentes en Berlín. El documento en cuestión, titulado "Manifiesto a los europeos", fue distribuido a mediados de octubre. ${ }^{4}$ Este documento constituye un excelente ejemplo del pacifismo que luchaba por abrirse paso en aquellos años. "Todo aquel al que le importe algo una cultura mundial común -escribía Nicolai- está doblemente comprometido a luchar por el mantenimiento de los principios en que ésta se basa. Y sin embargo, aquellos en quienes habría que haber supuesto tales sentimientos - principalmente los científicos y los artistashasta el momento han dicho casi exclusivamente cosas que hacen sospechar que han abandonado el deseo de que continúen las relaciones internacionales. Se han expresado con un espíritu hostil; no han hablado en defensa de la paz.m

Nicolai se daba cuenta de que los desarrollos científico-tecnológicos estaban transformando y empequeñeciendo el mundo: «las naciones de la gran península europea parecen hoy estar tan próximas como en los viejos tiempos lo estaban las ciudades-estado de cada una de las pequeñas penínsulas mediterráneas. El viajar está tan difundido, la exportación y la importación internacionales tan interrelacionados, que Europa -casi se podría decir el mundo entero- constituye una unidad».

Esta globalización de Europa - y en áltima instancia del mundo- 
planteaba la necesidad, o al menos la posibilidad, de nuevas formas de organización internacional, que en opinión de este pacifista alemán impedirían que «Europa sucumba». "La inestable y fluida situación en Europa, creada por la guerra, debe utilizarse -añadía- para transformar el Continente en una unidad orgánica. Técnica e intelectualmente, las condiciones están maduras para tal proceso.»

Nicolai nos plantea varias cuestiones. En primer lugar, la última cita nos muestra las esperanzas que surgieron a propósito de la Primera Guerra Mundial de que la creación de un tipo de gobierno internacional pusiese límites, o erradicase completamente, las guerras entre naciones. La Sociedad de las Naciones fue producto de semejante mentalidad, como también lo fue, a raíz de la Segunda Guerra Mundial, la Organización de las Naciones Unidas. Sin embargo, es un hecho evidente que estas organizaciones internacionales no tuvieron - o tienen- demasiado éxito en lo que a borrar de la faz de la Tierra las guerras se refiere, ni en evitar que, en tiempos de paz, se hayan utilizado diversos tipos de amenazas; la disuasión nuclear, por ejemplo.

El segundo aspecto con el que nos enfrentamos a propósito de Nicolai es el del pacifismo.

Los pacifistas rigurosos creen que nunca es permisible participar en la guerra, que jamás es posible proporcionar una justificación moral de ella. Como tal, el pacifismo es una postura extrema, pero es precisamente de esa radicalidad de donde extrae su fuerza. Elimina de raíz el problema de cuâles son los límites por los que podemos considerar el comienzo o el desarrollo de una guerra como justa o injusta.

Una pregunta que surge inmediatamente cuando se está considerando el tema de los científicos y la guerra, es cuántos de éstos fueron pacifistas. Si nos referimos a los científicos "de la naturaleza", a los especialistas en física, química, matemáticas, tecnología, etc., por lo que yo sé muy pocos, casi ninguno (Nicolai fue uno). El caso de Einstein, quien, como he apuntado, se sumó al manifiesto de Nicolai, se utiliza frecuentemente, pero cuando se considera toda su vida, nos encontramos con que Einstein no fue lo suficientemente consistente como para que se le pueda considerar realmente un pacifista. La célebre carta que dirigió al presidente Roosevelt el 2 de agosto de 1939,5 alertándole de que la fisión nuclear del uranio podía conducir ka la construcción de bombas [...] Una sola bomba de este tipo, transportada por barco y hecha explotar en un puerto, podría muy bien destruir todo puerto junto a parte del territorio que le rodease". El Proyecto Manhattan, que culminó con la fabricación de las dos bombas (de uranio y de plutonio) que se lanzaron sobre Hiroshima y Nagasaki en agosto de 1945, debió algo a aquella misiva.

La aversión que Einstein sentía por la Alemania de Hitler, el temor a que se construyese allí un arma nuclear, el realismo y sentido común que 
pocas veces le abandonaron, hicieron que el creador de las dos teorías de la relatividad no encontrase incompatible su carta de 1939 con manifestaciones que había realizado previamente. Como las que pronunció ante una asamblea de estudiantes pacifistas alemanes en $1930:^{6}$

Si el sagrado egoísmo sin limitaciones tiene graves consecuencias en la vida económica, es aún peor como criterio para las relaciones internacionales. El desarrollo de métodos mecánicos de guerra ha alcanzado tal nivel que sì no descubrimos pronto un medio de impedir la guerra, la vida humana resultará insoportable. La importancia de este objetivo sólo es comparable a la ineficacia de los esfuerzos emprendidos para lograrlo.

Naturalmente, la postura de Einstein ante Roosevelt es comprensible. Pero el que lo sea, no hace sino ahondar en la dificultad de sostener una postura pacifista coherente hasta el final, sin la cual, repito, deja de tener sentido.

Volviendo al «Manifiesto de los 93", tenemos que produjo inmediatamente violentas reacciones, especialmente entre los franceses, que por otra parte no se caracterizaban por sentir un gran amor por la cultura germana. ${ }^{7}$ Menos de un mes después de la publicación del manifiesto, el 3 de noviembre de 1914, la Académie des Sciences declaraba que:

La Academia tiene que recordar que las civilizaciones latinas y anglosajonas son las que han producido durante tres siglos la mayor parte de los grandes descubrimientos en las ciencias matemáticas, físicas y naturales, siendo asimismo los autores de las principales invenciones realizadas a lo largo del siglo Xxx. La Academia protesta, por consiguiente, contra la pretensión de ligar el futuro intelectual de Europa con el futuro de la ciencia alemana, y contra la afirmación de que la salud de la civilización europea se encuentra en'la victoria del militarismo alemán, solidario de la cultura alemana.

La indignación francesa continuó creciendo, y un profesor, Gabriel Petit, acompañado de un periodista de Le Figaro, Maurice Leudet, se encargaron de coordinar una obra colectiva en la que 28 especialistas (todos menos uno - William Ramsey- franceses) manifestaban su opinión sobre la ciencia alemana. El libro apareció en 1916 con el título Les allemands et la science. ${ }^{8}$ Naturalmente, casi todas las opiniones que se recogian sobre las contribuciones de los científicos alemanes eran muy críticas, mientras que se aprovechaba la ocasión para ensalzar la ciencia francesa. ${ }^{9}$ En el prefacio, Paul Deschanel, de la Académie Française y presidente de la Cámara de Diputados, afirmaba que uen la concepción germánica, la ciencia, la historia, la filosofía, la religión son fuerzas nacionales, como la armada, la diplomacia, el crédito. Desde este punto de vista, la ciencia no es algo universal y humano, sino un servicio del Estado. Como Alemania debe 
dominar a las otras naciones, la "ciencia alemana" debe ser superior a la de los otros pueblos. En palabras de Fustel de Coulanges, "el interés de Alemania es el fin último de sus infatigables investigadores"».

No eran estas acusaciones demasiado injustas. De hecho, en su oportunidad radica el hecho de que, en última instancia, aciencias - contemplada ésta como la obra de los científicos, sin los cuales no existe, no como un cuerpo de conocimientos, de cuyo origen no nos interesamos- y "Estado/nación» compartan algunos rasgos importantes en lo que se refiere a su relación con la guerra. Lo único que cabe achacar a estos intelectuales galos es el que lanzasen a los científicos alemanes acusaciones de las que, como la historia nos enseña, se salvan pocos científicos, ellos incluidos. La frase de Deschanel, "la ciencia no es algo universal y humano, sino un servicio del Estadom, se puede aplicar, en situaciones críticas (las más interesantes) a Alemania, pero también a Francia, a Estados Unidos, a la Unión Soviética, a Gran Bretaña, a China o al Japón. Aparentemente, sólo después de experiencias recientes muy traumáticas surgen voces relativamente numerosas que intentan matizar la concepción de la ciencia como un servicio del Estado. El caso de algunos científicos estadounidenses - como Robert Oppenheimer- tras la explosión de las bombas atómicas, es un buen ejemplo en este sentido. ${ }^{10}$

\section{Armamento nuclear: de Hiroshina a la «disuasión nuclear»}

El armamento nuclear plantea desde el punto de vista moral dos tipos diferentes de cuestiones: las relativas a su utilización en la guerra y las referentes a su posesión para fines disuasorios.

Tanto en uno como en otro caso, se suele utilizar la referencia al ius in bello para discutir su posible moralidad. Comencemos, sin embargo, por la utilización de armamento nuclear en la guerra. Como es bien sabido, sólo se dispone de un ejemplo en esta dirección: el lanzamiento de las bombas de uranio y plutonio sobre las ciudades japonesas de Hiroshima y Nagasaki en agosto de 1945. Ahora bien, es francamente difícil justificar semejantes bombardeos en base a los requisitos de fuerza mínima, discriminación y proporcionalidad. Comprobémoslo repasando sumariamente algunos aspectos de la fase final del Proyecto Manhattan.

En reuniones celebradas en abril y mayo de 1945, un "Comité de Objetivos» del Proyecto Manhattan, del que formaban parte militares y científicos (como Robert Oppenheimer y John von Neumann), seleccionó inicialmente cuatro blancos: Kioto, Hiroshima, Yokohama y el arsenal de Kokura, añadiendo Niigata como reserva. Muchas y variadas fueron las consideraciones que se manejaron a la hora de efectuar esta selección." Por una parte, se deseaba lanzar las bombas sobre ciudades - no centros industriales, demasiado pequeños y dispersos- que todavía no estuviesen 
muy dañadas por bombardeos previos (de Tokio prácticamente solamente quedaba en pie el palacio imperial). Uno de los propósitos era que el objetivo afectase lo más posible a la moral de los japoneses. Era conveniente, además, dirigir la bomba hacia el centro de la ciudad, no a las afueras, donde todo estaba más repartido y menos localizable. Por consiguiente, el requisito de discriminación, esto es, de evitar objetivos civiles, no se tenf́a en cuenta, al menos no demasiado, en aquellos planes. Salvando las anteriores limitaciones, el objetivo debía tener algún significado militar.

El 28 de mayo se decidía que los objetivos debian ser (por este orden): Kioto, la antigua capital imperial, Hiroshima y Niigata. Finalmente, se prescindió de Kioto. Sus numerosos tesoros artísticos y lo que significaba para Japón podian producir un excesivo resentimiento entre los japoneses, inclinándolos, en la difícil posguerra que se avecinaba, hacia los soviéticos. Como alternativa se introdujeron Nagasaki y Kokura.

Una pregunta fundamental es si Estados Unidos estaba completamente decidido a utilizar las bombas atómicas. "Cuando comenzamos a desarrollar la energía atómica -escribió en sus memorias el general Leslie Groves, que dirigió el Proyecto Manhattan-, los Estados Unidos no estaban en absoluto decididos a emplear armas atómicas contra ningún otro poder. Sin embargo, con la activación del Proyecto Manhattan la situación empezó a cambiar. Nuestro trabajo fue extremadamente costoso, tanto en dinero [2.000 millones de dólares] como en interferencias con el resto del esfuerzo bélico. Según pasaba el tiempo, al ir invirtiendo más y más dinero y esfuerzos en el proyecto, el gobierno se convenció cada vez más de que era necesario utilizar la bomba [...] Como lo expresó sucintamente Mr. Stimson [Secretario de Estado], el Proyecto Manhattan existía "para llevar la guerra a un final feliz más rápidamente de lo que se podría con otros medios y así salvar vidas americanas",.,12

Este argumento, el de "salvar vidas" de soldados estadounidenses, ha sido empleado con profusión tradicionalmente por el lado norteamericano para justificar el que Truman ordenase lanzar las bombas. Según esta historia, los dirigentes de Estados Unidos manejaban la cifra de medio millón de vidas salvadas. La apertura de archivos ha mostrado, sin embargo, que los cálculos militares daban ya entonces la cifra de 50.000. Estas cantidades comienzan a hacer sospechar sobre si se tenía en cuenta de alguna manera el requisito de la proporcionalidad.

Estaba también el temor a los soviéticos, hasta el punto de que se ha Ilegado a afirmar que las bombas atómicas se lanzaron más contra la Unión Soviética que contra Japón. Un problema importante es que en la conferencia de Yalta (febrero de 1945), Roosevelt y Churchill, deseosos de obtener la ayuda soviética contra Japón, habían cedido ante las demandas de Stalin, que se comprometió a entrar en la guerra entre dos y tres meses después de la derrota de Alemania. La disponibilidad de la bomba, y la 
creciente percepción del "peligro rojo", modificaban radicalmente la situación. Ahora Estados Unidos veía la posibilidad de que la guerra terminase antes de que la Unión Soviética entrase en la guerra, con lo que habría argumentos para negar a Stalin lo prometido en Yalta. Era, por consiguiente, urgente lanzar las bombas atómicas. Similar urgencia, pero por motivos completamente diferentes, surgía en los soviétícos. De hecho, Stalin firmó el 7 de agosto, el día después de Hiroshima, la orden para que el Ejército Rojo atacase a las fuerzas japonesas en Manchuria el día $9 .{ }^{13}$

Fuese por una u otra razón, el hecho innegable es que el 6 de agosto un bombardero B-29 estadounidense - el famoso Enola Gay- despegaba de la isla de Tinian con una carga mortífera, que lanzó sobre Hiroshima a las 8.15, hora local. Se trataba de Little boy, una bomba atómica de uranio, de unos 4.500 kilogramos de peso y unas 13.000 toneladas de TNT de potencia. Su efecto fue terrible. Virtualmente todo en un radio de 500 metros de la explosion fue incinerado. Los edificios situados hasta 3 kilómetros de distancia, destruidos. Un espeso hongo de humo ascendió hasta 12 kilometros de altura. A fines de año se estimaba el número de víctimas en 145,000 personas. Muchos otros llevaban, en forma de radiación, la muerte en su seno. Cinco años más tarde, los muertos sumaban 200.000.

Tres días más tarde (11.02 hora local) le tocaba el turno a una bomba de plutonio: Fat man. Pesaba algo más que Little boy, unos $5.000 \mathrm{~kg}$, pero tenía la misma potencia. Su objetivo fue Nagasaki. Las víctimas fueron 70.000, menos que en Hiroshima debido a errores en el lanzamiento.

Estas cifras echan por tierra cualquier recurso justificativo que pretenda beneficiarse de los requisitos de la fuerza mínima y la proporcionalidad.

Pasemos ahora a la "disuasión». (Recordemos en este punto que la estrategia nuclear de Estados Unidos se basa en un concepto que fue introducido por el Secretario de Defensa McNamara en 1967: «La piedra angular de nuestra estrategia política sigue siendo disuadir de todo ataque nuclear deliberado contra Estados Unidos y sus aliados, manteniendo una capacidad sumamente fiable de infligir un grado de daño inaceptable a cualquier agresor o combinación de agresores en cualquier momento durante un intercambio nuclear estratégico, aun después de haber recibido nosotros un primer ataque por sorpresa».)

Existen teóricos morales que opinan que hay algunos usos posibles del armamento nuclear que no violarian ninguno de los requisitos que estamos considerando. Ahora bien, la disuasión ha supuesto siempre amenazas de utilizar el armamento nuclear para la destrucción intencionada de poblaciones civiles, y esto violarfa claramente el requisito de discriminación y casi sin duda también el de proporcionalidad.

No podemos olvidar tampoco - ni siquiera con un instrumento tan poderoso como la amenaza de utilizar armas nucleares - algunas leccio- 
nes que nos ha dado la historia. Freeman Dyson, un físico distinguido, ha apuntado en este sentido lo siguiente: ${ }^{4}$

Es bueno hacer que la gente tema a la guerra nuclear. Pero el miedo no basta. La generación que creció después de la Primera Guerra Mundial cstaba bien adoctrinada sobre los horrores de la guerra de trincheras [...] veían, cada día, a las viudas, a los huérfanos y los supervivientes lisiados de la guerra. Podían recordar las matanzas de Verdún y de Passchendaele, como nosotros recordamos la matanza de Hiroshima, y, ciertamente, sentían miedo. Durante los veinte y los treinta florecieron movimientos pacifistas, y los programas en pro del desarme gozarnn de considerable apoyo público. El temor de una repetición de la Primera Guerra Mundial era auténtico y casi universal. Pero los seres humanos, para bien o para mal, están constituidos de tal manera que no dejan que sus vidas sean dominadas por largo tiempo por el temor.

El que tras Hiroshima y Nagasaki no se hayan vuelto a emplear bombas nucleares en conflictos bélicos, y que las grandes potencias no se hayan enfrentado de manera directa militarmente, es, ciertamente, un buen argumento en contra de la opinión de Dyson, y en favor de la disuasión nuclear, pero si finalmente lo es, no lo sería desde el punto de vista moral, sino del práctico, de una moral utilitarista.

\section{Otra dimensión moral del desarrollo del armamento: el bayardismo}

En un libro que publicó en 1925, Callinicus, a Defense of Chemical Warfare, J.B.S. Haldane describía una curiosa forma de honor practicada por el caballero Bayard en la Francia del siglo XV. ${ }^{15}$ Bayard otorgaba privilegios a aquellos que eran capturados luchando según las antiguas costumbres de la guerra tradicional. Pero cualquier hombre que fuese capturado utilizando el mosquetón, u otros instrumentos de pólvora, era matado inmediatamente. Era moral, creía Bayard, matar con medios tradicionales, pero bárbaro emplear los últimos métodos.

Detrás de toda muerte hay, es evidente, un dolor universal, cósmico, no importa su víctima o situación. En este sentido, no es difícil pensar que los argumentos bayardianos carecen de toda justificación. Sin olvidar que corren en contra de la historia, con sus avances científico-tecnológicos. Sin embargo, no deja de ser menos cierto que los nuevos, más poderosos, instrumentos de muerte desarrollados para su utilización en conflictos bélicos, pueden introducir nuevos tipos de horror (también, acaso, de "humanidad»).16 "La utilización de instrumentos -ha señalado Robert Proctor- tiene consecuencias - simbólicas, prácticas, políticas, ecológicas-e, incluso si toda muerte en guerra es una tragedia, los medios mediante los cuales tales muertes se producen son distinguibles. Si todos los medios son igualmente buenos ( $u$ horribles) ¿dónde deja esto la idea de castigos 
crueles y raros? ¿O la Convención de Ginebra? ¿O la repulsión que sentimos ante la idea de que los fines justifican los medios? ¿Dónde queda nuestro rechazo ante los militares disfrutando de una bonanza de investigación, mientras que existen carencias en prioridades más humanas? "17

\section{Trascendencia y compartamentización en la ciencia}

Cuando se habla de la guerra y los científicos, hay otro aspecto a considerar, aunque su relación con el tema anterior no sea tan inmediata como en las consideraciones anteriores.

Entre muchos científicos de nuestro siglo (y sobre todo entre los físi$\cos$ ), ha proliferado una actitud, o filosofía, según la cual uno de los principales atractivos de la ciencia es el de que constituye, como ha señalado recientemente Paul Forman, una huida de la vida diaria con su penosa crudeza y desoladora vaciedad; una huida de un mundo que nos impone constantemente la penosa obligación de elecciones morales y asunción de responsabilidades; una huida hacia un mundo donde reina lo objetivo; una evasión, en definitiva, hacia la "trascendencia».18 Firmes defensores de semejante visión de la ciencia fueron científicos del calibre de Einstein, Planck y Heisenberg. En Los Álamos, en pleno desarrollo del Proyecto Manhattan, el gran matemático John von Neumann aconsejó a Richard Feynman, uno de los grandes genios de la física posterior a la Segunda Guerra Mundial, que «no tenía por qué sentirse responsable del mundo en el que vivías. Y el entonces joven físico siguió aquel consejo, desarrollando, como explicó en su autobiografía, uun poderoso sentido de irresponsabilidad social, que hizo de mí una persona muy feliz desde entonces". ${ }^{19}$ Fueron, sobre todo, los físicos que crearon y desarrollaron la mecánica cuántica los que vivieron en la idea de que existen, o que es posible y deseable establecer, fronteras definidas entre las esferas política, moral y científica.

Esta actitud se ha visto favorecida por la orientación que ha tomado una parte muy importante de la investigación científica durante la segunda mitad de nuestro siglo. El general Groves impuso una regla de hierro en todas las actividades del proyecto Manhattan: "La compartamentización era, para mí, el mismo corazón de la seguridad. Mi regla era sencilla e imposible de malinterpretar: cada persona debería saber todo lo que necesitaba conocer acerca de su trabajo y nada más. La adhesión a esta regla no sólo proporcionó una medida adecuada de seguridad, sino que mejoró mucho la eficacia general haciendo que la gente se limitase a lo que tenía que hacern. 20

Esta filosofía que Groves diseñó para un proyecto científico-tecnológico militar, se trasladó, después de la guerra, a la mayoría de la investigación científica desarrollada con fondos militares, conviertiéndose de esta manera en una auténtica filosofía de toda la investigación científica. 
El punto es que la filosofia trascendental y la metodología compartamentalista no son las más adecuadas para tomar partido en lo relativo a si es moralmente conveniente o no la participación de los científicos en las guerras, o en actividades de índole militarista en tiempos de paz. Se podría decir que la trascendentalidad y la compartamentización constituyen grandes enemigos de la moral y la ética.

Íntimamente relacionada con la postura trascendental está la idea de que no importa cuáles puedan ser sus aplicaciones, la ciencia en sí es pura; que la ciencia puede ser política en sus aplicaciones, pero no en su origen o estructura. La discusión sobre la posible "neutralidad» de la ciencia, sobre su ambivalencia, no es, naturalmente, nueva. ${ }^{21}$ Platón se detenía en demostrar que aquellos más capaces de curar son también los más capaces de hacer daño, que aquellos más competentes en decir la verdad son también los más hábiles para mentir. Pero no nos remontemos a la Grecia clásica, vayamos mucho más cerca, a 1938, cuando el célebre físico Lord Rayleigh utilizaba parte de su conferencia inaugural en una ocasión tan notoria como el congreso de la British Association for the Advancement of Science celebrado en Cambridge, para tratar el tema de "La ciencia y la guerra".22

El argumento de Rayleigh giró en torno a la idea de que los científicos no buscan instrumentos que sirvan para las guerras, sino que se encuentran con ellos sin pretenderlo. "Yo creo - manifestaba- que toda la idea de que los científicos son especialmente responsables [por la aportación de la ciencia a la guerra] es una equivocación nacida de un conocimiento incompleto del auténtico curso del proceso de descubrimiento.» Y para apoyar esta declaración recurría a ejemplos: ${ }^{23}$

En el curso del estudio sistemático de la química de los compuestos del carbono era inevitable que se intentase averiguar cuál era la acción del ácido nítrico en sustancias como el benceno, tolueno, glicerina, celulosa y otras. Nadie podía prever los resultados. En el caso del benceno, tenemos el nitrobenceno, la clave para la industria de los tintes de anilina. En el caso de la glicerina, Sobrero obtuvo en 1846 el altamente explosivo líquido denominado nitroglicerina. No intentaba hacer ningún mal, y de hecho su descubrimiento permaneció olvidado durante muchos años, hasta que Nobel se interes 6 por el tema en 1863, y demostró cómo mezclando nitroglicerina con otras sustancias se podian preparar explosivos sólidos que era posible manejar con seguridad, La dinamita fue uno de ellos. Demostraron ser extremadamente útiles en las artes de la paz; por ejemplo, en la mineria y en la construcción de túneles de ferrocarriles, como los que atraviesan los Alpes. También fueron utilizados por los Fenians ${ }^{24}$ irlandeses en los atentados con dinamita de los ochenta. Estos atentados no tuvieron mucho éxito, pero por lo que yo sé nadie sintió la tentación de acusar a la ciencia de ellos...

Tras este ejemplo, Rayleigh utilizaba también el de los gases venenosos, en particular el del gas mostaza, al que se recurrió durante la Primera 
Guerra Mundial. Su argumento se limitaba a considerar la edición de 1894 del Dictionary of Chemistry de Watts, en que el gas mostaza aparecía, bajo el encabezamiento de "sulfuro de dicloroetilo», en un artículo de menos de cuarenta palabras. "Tras mencionar el método de separación de Victor Meyer -escribía Rayleigh (p. 18) -, se dejaba de lado a la sustancia con las palabras "aceite, muy venenoso e inflama violentamente la piel".s Otros dieciséis compuestos -apuntaba el físico inglés- eran descritos con una extensión comparable en aquel diccionario de química. "Por último, al final de la página comenzaba un largo artículo sobre el cloroformo. Esta sustancia, como saben ustedes, ha eliminado muchos dolores, y de acuerdo al mismo principio el investigador que lo produjo fue, sin duda, un ángel. El problema es que todos los investigadores procedían exactamente según el mismo espíritu, el espíritu de la curiosidad científica, y sin ninguna posibilidad de saber si el tema de su trabajo les convertirá en demonios, o soñadores, o ángeles.»

Aunque contiene datos correctos, la reconstrucción que hacía Rayleigh de las relaciones entre ciencia y guerra es, sin duda, demasiado parcial. En primer lugar porque omitía considerar el hecho de que también eran científicos los que aplicaban, cuando no creaban, ese conocimiento -obtenido previamente en los casos que citaba- a la guerra.

Cuando, en 1914, los militares alemanes se dieron cuenta de que la guerra no sería tan rápida como habían previsto, recurrieron a los científicos. Al gran Fritz Haber y a otros químicos (entre ellos Carl Duisberg, uno de los directores de la corporación de tintes Bayer, y Walther Nernst) les pidieron que desarrollaran métodos químicos para utilizar contra las líneas enemigas en el campo de batalla. En octubre y noviembre de 1914, mientras Haber llevaba a cabo distintos intentos sin éxito, Duisberg y Nernst prepararon, utilizando las instalaciones de la Bayer, varios tipos de granadas y bombas incendiarias, y comenzaron a estudiar gases irritantes no letales, que, por lo visto, consideraban utilizables sin violar los acuerdos de las Convenciones Internacionales de La Haya de 1899 y $1907 .{ }^{25}$. En este último dominio desarrollaron un proyectil lleno de gas, con el pretendían hacer inhabitables las líneas enemigas durante el tiempo suficiente para tomarlas. En el otoño e invierno de 1914 utilizaron semejante arma, pero con escaso éxito militar: ${ }^{26}$

El Ejército alemán se mostró desilusionado con los resultados obtenidos, pero no obstante ordenó que se continuase la producción de los proyectiles. Al mismo tiempo, el general Erich von Falkenhayn pedía que los expertos produjesen gases que inutilizasen permanentemente -incluso llegando a la muerte- al enemigo. Duisberg creía que la resolución de este problema requeriría un esfuerzo científico exagerado, pero, aunque de mala gana, continuó investigando el asunto.

Sin embargo, el genio químico de Haber no necesilaba tanto, y, prác- 
ticamente al mismo tiempo que Duisberg ponía dificultades y solicitaba más recursos, él encontraba una solución en principio simple e ingeniosa: un gas venenoso de cloro, que se lanzaría desde las propias líneas alemanas, utilizando contenedores apropiados y aprovechando vientos adecuados. Haber explotó la posibilidad de licuar el cloro a la temperatura ambiente, utilizando presiones moderadas. Comprimido en contenedores cilíndricos, podía ser luego expulsado igual que la gaseosa de un sifón.

No es necesario continuar ofreciendo detalles de la introducción de los gases tóxicos en la Gran Guerra para entender que la historia real es, en este caso, que también utilizaba Rayleigh, muy diferente a la que él había esbozado.

Otro motivo para descartar la argumentación de Rayleigh es que incluso aunque su descripción fuese correcta $-y$, como acabamos de ver, existen motivos para dudar de su verosimilitud-, la situación ha cambiado -continúa cambiando (biotecnología) - desde entonces. Como ha señalado Robert Proctor, la supuesta neutralidad de la ciencia y la tecnologia «describe únicamente las tecnologías más sencillas, los principios más abstractos. Las siete máquinas sencillas, acaso, o las reglas aritméticas, pueden ser neutrales en este sentido. Pero una verdad abstracta a menudo esconde una mentira concreta. "Los cañones no matan a la gente, lo hace la gente." ¿Pero es sorprendente que una sociedad que se rodea de cañones los termine utilizando? "Una espada recién afilada", reza el proverbio africano, "marcha sola hacia el siguiente pueblo". Los instrumentos, sabemos, tienen usos diversos; el cuchillo comprado para cocinar puede utilizarse para matar. Sin embargo, cuchillos y palancas no son de lo que trata la moderna tecnología basada en la ciencia. Una central nuclear, un misil de crucero, un acelerador lineal, difícilmente pueden ser utilizados para otros fines dilerentes a aquellos para los que fueron diseñados. Las tecnologías basadas en la ciencia están cada vez más dirigidas a fines específicos: los medios restringen los fines; no es ya tan fácil separar el origen de un instrumento de su uso previsto. ¿Que significa "abusar" de un misil de crucero o de una bomba de neutrones?».27

La denominada "militarización de la ciencia» durante la segunda mitad de nuestro siglo, esto es, la influencia que las Fuerzas Armadas han desempeñado y desempeñan en la dirección que toma y resultados alcanzados por la investigación científica, ${ }^{25}$ muestra que una parte muy importante - cuantitativa y cualitativamente- de la ciencia se enmarca en el mismo contexto en el que tiene su razón de ser la discusión sobre la moralidad, o límites morales, de la guerra.

La idea de la neutralidad de la ciencia se relaciona también con visiones metodológicas de la naturaleza y estructura de la ciencia que conviene matizar, si no erradicár. Son los planteamientos de corte inductivista o empiricista, incluso los logicistas; aquellos en los que se pasa por alto el 
«contexto de descubrimiento» en favor del "contexto de justificación», Lo principal es, según estas visiones, el artículo o la monografía publicados, no el contexto - social, individual - del que surgieron. El contenido de la ciencia, los resultados que la forman, son algo así como un conjunto ideal, platónico, popperiano-3, de resultados a los que alguien - un científicollegará -o no; esto también es posible- en algún momento del futuro. Ocurre, no obstante, que, como toda una generación de sociólogos está demostrando, la ciencia contiene una buena dosis de contingencia, de aintrascendentalidad.${ }^{29} \mathrm{El}$ entorno en el que se mueven, los medios de que disponen, los prejuicios o los deseos que animan a los científicos, influyen en el contenido de la ciencia de una manera mucho más profunda de lo que hasta hace no mucho se había supuesto. "Haciendo que los resultados de la investigación científica parezcan más decisivos e inmediatos de lo que en realidad son - ha escrito recientemente Gerald Geison en un estudio de Louis Pasteur-, la información publicada tiende a ocultar la maleabilidad de la naturaleza. Erradica de la ciencia sus rasgos más creativos, transmitiendo la impresión de que imaginación, pasión y arte no tienen lugar en la investigación científica. Hace que parezca como si los logros e innovaciones científicas resultasen no de la apasionada actividad de mentes y manos comprometidas, sino de la aquiescencia pasiva de los preceptos estériles del denominado Método Científico, ${ }^{30}$

Pero no es así. Los resultados de la ciencia no surgen habitualmente - desde luego no en las últimas décadas- de la manera que describía Lord Rayleigh. La ciencia es, como nos advierte Geison, más maleable de lo que se suele pensar, y así el papel, y la responsabilidad, del científico adquiere una nueva dimensión. Ese papel, esa responsabilidad, se convierten, en definitiva, en elementos centrales en la dimensión moral, al igual que en otras, de un producto - la ciencia- cuyo contenido parece estar no inscrito en libros inescrutables, sino en la acción de un grupo de seres humanos: los científicos.

\section{NOTAS}

1. Ver, por ejemplo, Jeff McMahan, "Guerra y paz», en Peter Singer (ed,), Compendio de ética, Madrid, Alianza, 1995, pp. 521-536.

2. M. Born, My Life. Recollections of a Nobel Lautreate, Nueva York, Charles Scribner's, 1978, pp. 160-162.

3. Publicado en Hermann Kellermann, Der Krieg der Geister, 1914, Desden, Vereinigung Heimat und Welt, 1915, pp, 64-68.

4. Este manifiesto se incluye en el conocido libro de Nicolai, Die Biologie des Krieges, Zurich, Orell Füssli, 1916. Existe una traducción al castellano, Biología de la guerra, Santiago de Chile, Ercilla, 1937, en la que el manifiesto aparece en las pp. 38-40; sin embargo, la calidad de la traducción es pésima, por lo que he traducido de nuevo el documento.

5. Reproducida en José M. Sánchez Ron, El poder de la ciencia, Madrid, Alianza, 1992, pp. $324-325$. 
6. A. Einstein, "Discurso ante una asamblea de estudiantes pacifistas», reproducido en Ideas y opiniones, Barcclona, Antoni Bosch, 1981, p. 82.

7. Un buen ejemplo en este sentido es el libro de René Lote, Les origines mystiques de la Science «allemande», París, Librairie Félix Alcan, 1913, en el que se muestra a Alemania como una potencia mística de opresión, deseosa de dominar el mundo.

8. Paris, Librairie Félix Alcan.

9. El principal -y casi único- *disidente», con relación al tono general de las intervenciones, fue un profesor de la Facultad de Medicina de Montpellier, Grasset, que se limitó a participar en el libro con una carta en la que se negaba a aceptar la idea de una ciencia alemana y una ciencia francesa. "¿Qué se puede reprochar a los sabios alemanes? -escribín-. No sus doctrinas científicas, no sus opiniones políticas, no su amor por su país, no los errores de su patriotismo ciego [...] Sólo tenemos que reprocharles una cosa, el haber mezclado pun. tos de vista disparatados y el haber expresado sus opiniones de ciudadanos alemanes amparandose en su auturidad de sabios."

10. Herbert F. York, The Advisors. Oppenheimer, Teller, and the Superbomb, Stanford, Stanford University Press, 1976; In the Matter of J. Roben Oppenheimer, Cambridge, MA, The MTT Press, 1971,

11. Barton J. Bernstein, "Hiroshima y Nagasakin, Polúica Exterior $I X$, n. 44 (abril-majo de 1995). pp. 41-54; y Leslie Groves, Now It Can Be Told, Nueva York, Harper \& Brothers, 1962, cap. 19, «Choosing the target".

12. Now It Can Be Told, p. 265.

13. Sobre estas cuestiones, consultar. David Holloway, Stalin and the Bomb, New Haven, Yale University Press, 1994.

14. F. Dyson, "Las bombas y la poesía», en F. Dyson, R. Aron y J. Robinson, Valores en guerra, México, FCE, 1987, pp. 42-43.

15. Existe versión al castellano de esta obra: Calínico o una defensa de la guerra quínica, Madrid, Revista de Occidente, 1926.

16. En el informe que preparo en 1919 para la British Association for the Advancement of Science, Harold Hartley, director del Departamento Anti-gas británico, argumentaba en este sentido de la mancra siguiente: "El juicio de las generaciones futuras sobre la utilización de gases puede verse influido por el patético cuadro de [John Singer] Sargent en el que se muestran las primeras víctimas producidas por el gas mostaza en Ypres, pero al contemplar ese cuadro no se debe olvidar que el $75 \%$ de los hombres cegados que dibujó estaban listos para volver al frente tres meses despuess, y que su destino habria sido infinitamente peor si sus miembros y nervios hubiesen sufrida los efectos de un poderoso explosivo", "Chemical warfaren, Report of the Eighty-seventh meeting of the British Association for the Advancement of Science, Londres, John Murray, 1920, pp. 393-402; p. 398.

17. R.N. Proctor, Value-Free Science?, Cambridge, MA, Harvard University Press, 1991, p. 269.

18. P. Forman, "Física, modemidad y nuestra evasión de la responsabilidad», Arbor, n." 577-578 (enero-febrero 1994), pp. 51-74.

19. Richard P. Feynman, ¿Está Vd. de broma, Sr. Feynman?, Madrid, Alianza, 1987, p. 154.

20. Groves, Now It Can Be Told, p. 140.

21. Ver, por ejemplo, J.M. Sánchez Ron, "El conocimiento científico, prenda de felicjdad?n, en Jordi Nadal (coord.), El mundo que viene, Madrid, Alianza, 1994, pp. 221-246.

22. Lord Rayleigh, «Part I: Vision in nature and vision aided by science. Part II: Science and warfare», British Association for the Advancement of Science. Report of the Annual Meeting 1938, Londres, Office of the British Association, 1938, pp. 1-20.

23. Ibid., pp. 17-18.

24. Miembros de un grupo revolucionario secreto irlandés qué se formó en Nueva York hacia 1858 para liberar Irlanda del control ingles.

25. En la sección a del artículo XXIII de la Convención de La Haya de 1899 se prohibía "la utilización de veneno o armas envenenadas"; ademass, en la Declaración firmada se señala- 
ba que alos poderes contratantes están de acuerdo en abstenerse de utilizar proyectiles cuyo objeto sea la difusión de gases asfixiantes o nocivos». En la Segunda Conferencia Internacional de La Haya (1907) no variaron los términos. Ver Stockholm International Peace Research Institute, The Problem of Chemical and Biological Warfare, vol. III (CBW and the Law of War), Estocolmo, Almquist \& Wiksell, 1973. pp. 152-153.

26. Es importante señalar que los alemanes no fueron los únicos en intentar utilizar gases con fines bélicos en los primeros compases de la guerra. La propia existencia de las mencionadas previsiones en la Convenciones de La Haya indica que la posibilidad de la guerra química ya se encontraba relativamente extendida a finales del siglo xIX. En agosto de 1914 los franceses ya disponian de cartuchos de gases, preparados por los Cuerpos de Ingenieros franceses; más tarde (en marzo de 1915) utilizaron proyectiles que contenían un gas irritante, cl bromoacetato de etilo. Por su parte, los británicos habían efectuado algunas pruebas adoptando un gas lacrimoso, el yodoacetato de etilo, al que designaban SK, ya que habia sido descubierto en el Imperial College, en el barrio londinense de South Kensington.

27. R.N. Proctor, Value-Free Science?, pp. 2-3.

28. Sobre este punto, ver Paul Forman, "Behind quantum electronics: National security as basis for physical research in the United Statesw, Historical Studies in the Physical and Biological Sciences, 18 (1), 149-229 (1987).

29. Ver, por ejemplo, J. Manuel Iranzo et al., Sociología de la ciencia y la tecnología, Madrid, CSIC, 1995, y Carlos Solís, Razones e intereses, Barcelona, Paidos, 1994.

30. G.L. Geison, The Private Science of Louis Pasteur, Princeton, Princeton University Press, 1995, p. 14. 